\title{
J(৫)
}

Received: 15.05 .2020

\section{TEZCAN, S. Topkapı Sarayı Oğuznâmesi, İnceleme, Yap1 Kredi Yayınları, İstanbul, 2020, ss. 308, ISBN: 978-975-08-4699-1}

\author{
Osman Fikri SERTKAYA \\ İstanbul/ Turkey \\ E-mail: sertkaya of $46 @ g m a i l . c o m$
}

Oğuznâme'ler üzerinde yapılan son çalışmalar olarak şu yayınları zikretmek gerekiyor.

1. ERCilasun, A. B. (2019). Nehir Destan Oğuznâme (Oğuz Bitig), İstanbul: Dergâh Yayınları.

İrili ufaklı hacimli 26 eserin toplu olarak değerlendirildiği bu eserin sonunda yazarın konu ile ilgili 18 makalesi ve bildirisi yer almaktadır.

2. YILMAZ-ÖNDER, S. (2019). Yazıcızâde Ali'nin Oğuznâmesi, Metin-TercümeSözlük-Tıpkıbasım, İstanbul: Dergâh Yayınları.

İstanbul, Topkapı Sarayı kütüphanesi, Revan bölümü, 1391'de kayıtlı nüsha esas alınarak hazırlanan metin. 


\section{$J(\Theta)$}

3. DEMir, N. (2020). Ebulgâzi Bahadır Han: Şecere-i Türk, Türk'ün Soy Kütüğü, Ankara: Altınordu Yayınları.

Yayında aslı Çağatay Türkçesi ile olan eserin Türkiye Türkçesine çevirisi, kaynakça ve özel adlar dizini yer almaktadır.

TEZCAN'ın çalışması, Arap harfli metninin Yazıcıŏlu Ali'nin Topkapı Sarayı Müzesi Kütüphanesi, Revan Bölümü, 1390 numarada kayıtlı Tevârîh-i Âl-i Selçuk adlı yazmasının baş tarafındaki boş sayfalara (1a, 2a-b) yazılan 65 satırlık bir metin hakkındadır. Yazıcızade Oğuznâmesi veya Topkapı Sarayı Oğuznâmesi adı ile bilinmektedir.

Topkapı Sarayı Oğuznâmesi üzerinde bugüne kadar Rıdvan Nafiz EDGÜER (1934, 1939), Orhan Şaik GöKYAY (1938, 1973, 2006), Fahrettin KIRZIOĞLU (1952, 2000), Kamil Nerimanoğlu VeliYeV ve Fehri Agaoglı UgurLu (1993), Bahaeddin ÖGEL (1995), Fatma Ahsen TURAN (1997) ve Mustafa Sinan KAÇALIN $(2006,2017)$ çalışmıştır.

TEZCAN'ın Topkapı Sarayı Oğuznâmesi başlıklı incelemesi ise ilk kez açıklama notlarını ihtiva eden kitap yayınıdır. Topkapı Sarayı Oğuznâmesi Yapı Kredi Yayınları tarafından Mart 2020'de yayımlanmıştır. İnceleme 14 Eylül 2017'de geçirdiği kalp krizi ile vefat eden TEZCAN'ın eşi Nuran TEZCAN'ın Semih Tezcan'dan Sonra (s. 9-13) başlıklı takdimi ile başlamaktadır. Sonra Önsöz (s. 15), Giriş (s. 17-22), Araştırma Tarihi (s. 23-29), Birkaç Açıklama (31-32), İşaretler (s. 33), Yazı Aktarımı (s. 3542), Dizimli Metin (s. 43-53) bölümleri gelmektedir. TEZCAN, eserin hece vezninin çeşitli ölçüleri ile yazıldığını söyleyerek Dizimli Metin bölümünde bunları göstermiştir. Notlar (s. 55-253) bölümünde eserde geçen 65 satırın kelimeleri açıklanmıştır. Eserde daha sonra, Topkapı Sarayı Oğuznâmesi'nde Geçmeyen, Sadece Dede Korkut Oğuznâmeleri’nden Bilinen Oğuz Kişileri (s. 254), Topkapı Sarayı Oğuznâmesi’nde Geçen, Dede Korkut Oğuznâmelerinde Geçmeyen Oğuz Kahramanları (255), Bibliyografya ve Kısaltmalar (257-273), Dizin Üzerine Açılamalar (s. 274), Dizin (s. 275-306) ve Tipkıbasım (s. 307) bölümleri yer alır.

TEZCAN'ın uzun yıllar boyunca titizlikle hazırladığı, ancak tamamlayamadığı bu eser yine Yapı Kredi yayınları arasında Nisan 2001'de yayımlanan Dede Korkut Oğuznâmeleri Üzerine Notlar eserinin metot olarak aynısıdır. 


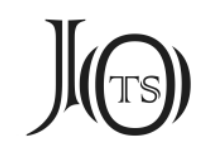

Eseri dikkatli bir şekilde okudum. Eksik olan bazı yerler ile farklı anladı̆̆ım yerleri bu tanıtmam ile değerlendiriyorum.

Ban kelimesi 'keçeden yapılmış büyük çadır' (s. 58) şeklinde anlamlandırılmış ve "kelime Farsça bām, bān 'dam, kubbe' ile ilişkili olabilir. DKOÜN 81 ve devamindaki notuma bkz." açıklaması konulmuş. Ancak metindeki ibare bān değil bān evlü'dür ve ban ev ibaresi Anadolu ve Rumeli ağılarında /b-/ > /m-/ değişmesi ve ilerleyici benzeşme yüzünden $e v>a v$ şeklinde ince sıradan kalın sıraya geçme yolu ile ban ev > manav şeklini almıştır. Eski Türkçe metinlerdeki ban ev ibaresi ise 'ağaç/ahşap/tahta ev' demektir, 'keçe ev' değil. Konunun geniş değerlendirmesi için bk. Uçar 2019: 21-42.

\section{1. satır}

arl suya batdukda ābdestlï Oguz 'temiz suya daldığında aptesli Oğuz'. TEzCAN'ın açılaması doğrudur. Çocukken Adana'da yaşlıların çırıl çıplak olarak akarsuya üç kez tamamen battıklarında gusül abdesti aldıklarını söylediklerini duymuştum. Olay Haldun TANER'in Sancho'nun Sabah Yürüyüşü adlı kitabındaki bir hikâyeye kadar gelmiştir.

\section{5. satir}

TEZCAN, țolamalı bekter donun sökülmesün okuduğu cümleyi "Dolamalı bekter zırhın sökülmesin” şeklinde çevirmiş (s. 105-106), ancak sökül- fiili hakkında bir açılama yapmamıştır. TEZCAN'dan sonra bulunan Günbed yazmasında zırh ile ilgili sökdür- fiili geçiyor. TEZCAN, Günbed yazmasını görseydi bu iki fiil hakkında açıklama yazardı. Şimdi açıklamayı ben yazayım.

yeni ḳısḳa demür donlar er köynegi

güni gelse, demi düşse

çalışanda dalaşanda yey yahadan sökdürmese

yeni kısḳa demür donlar neye yarar, neye yarar?

"Yeni kısa demir giysiler, er gömleğidir; Günü gelse, zamanı uygun düşse, çarpıştığında vuruştuğunda (hasmının) yen yaka(sın)dan parçalamazsa, yeni kısa demir giysiler neye yarar, neye yarar?". (11/14-12/2) 


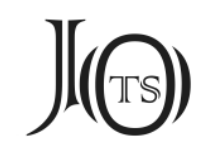

Sök- fiili Azerbaycan Türkçesinde (Orucov 2006b: 114b) şöyle yer almıştır:

1. Kurulmuş bir şeyi uçurtmak, dağıtmak, yıhmak, 2. Tikişini açmak, 3. Ham torpağı işlemek, açmak, kaldırmak, 4. Işıklaşmak, ışıklaşmağa başlamak, ışıklandırmak, 5. (mecazen) Parçalamak, dağıtmak, mahv etmek (bu menada bezen "söküp-dağıtmak" şeklinde işlenir.

Sök- fiilinin fiilden fiil yapan $\{-1-\}$ eki ile teşkil edilen sök-ü-l-ve fiilden fiil yapan \{-dUr-\} eki ile teşkil edilen sök-dür- şekilleri 'dikişi açmak' anlamında değildir. Savaş ile ilgili metinlerde mecazen 'parçalamak, ezmek, dağıtmak' anlamındadır. Ben yazmada geçen țolamalı bekter donuy sökülmesün cümlesini "Dolamalı bekter zırhın parçalanmasın" şeklinde anlıyorum.

Yazı aktarımı bölümünde 6. satırda biliklü (s. 35) okunan kelime 10. satırda Dede Korkut bilgilï (s. 36), 20. satırda Dede Korkut biliklü (s. 37) okunmuş. Kelimenin imlâsı ise her üç örnekte de Arap harfleri ile (بكلكو) şeklinde aynı olarak geçer. TEZCAN, 6. ve 20. satırda biliklü okuduğu kelimeye Dizin s. 279'da 'kehânet sahibi olan', bilgilü kelimesine ise 'kâhin', bilü (s. 280) kelimesine ise 'geçmişe ve geleceğe ilişkin bilgi' anlamı vermiş.

Kelime Eski ve Orta Türkçede bilig, bilgi, biliglig ve bilgilig şekillerindedir. Dolayısıyla Dede Korkut'ta ancak yuvarlaklaşma ile bilgilü şeklinde okunabilir, biliklü okunamaz. Çünkü $\{-(\mathrm{X}) g\}$ eki düşer ve kelime bili bilü şeklini alır. $\{-(\mathrm{X}) \mathrm{k}\}$ eki ise düşmez. Dolayısıyla dizindeki bilikli kelimesi bilgilü maddesi ile birleştirilmelidir.

\section{0-22. satırlar}

Dede Ḳorḳu biliklü yédi bilüsin vérsün

Emìr Sülmān ugiurlu [yédi uġrın] vérsün

Salır Kazan sa'ādetlï yédi sa'ādetin vérsün

Bayındır Hān devletlü yédi devletin vérsün

Alp Arız [hürmetlü yedi hürmetin] vérsün

Blyıġı kanlu Bügdüz Emen heybetlü yédi heybetin vérsün 


\title{
$J(\Theta)$
}

TEZCAN, şöyle diyor:

\begin{abstract}
“Bu satırlarda Dede Korḳut'un yédi bilü'si Emir Sülmān'ın yedi ugrı, Salur Kaazan'ın yédi sa'ādeti, Bayındır H̦ān'ın yédi devleti, (eğer yapılan ekleme doğruysa) Alp Arız'ın yedi hürmeti (?) ve Bügdüz Emen'in yédi heybeti geçmektedir. Şimdiye değen birçok yerde yédi sayısı üzerinde durulmuş, ise de (örn. Gökyay 1973, Ro. $304=2006$ baskısı 1026) burada altı Oğuz büyüğüne ilişkin olarak sayılan yédi'leri açıklayabilecek durumda değiliz. (s. 117)."
\end{abstract}

Y1l 1965. Türkoloji bölümü ikinci sınıf öğrencisiyiz. Eski Türk Edebiyatı dersinde hocamız Prof. Fahir İz'in Eski Türk Edebiyatında Nesir ve Eski Türk Edebiyatında Nazım adlı kitaplarını okuyacağız. Hocamız bize ön bilgileri veriyordu. Bunlardan birisi de yardımcı ünsüz/bağlayıcı ünsüz/kaynaştırma ünsüzü şekillerinde söylenen /y/ ünsüzü hakkındaydı. Müstensihin kelimeyi birlikte yazdığında bu ünsüzün yardımcı ünsüz olarak okunduğunu (Örnek: بيلكيلييليكي bilgili-y-

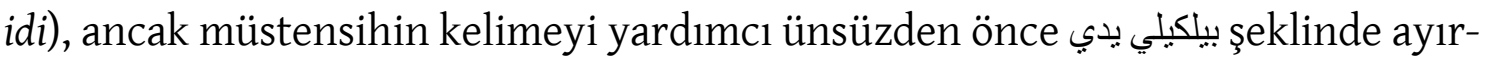
dığı zaman kelimenin iki ayrı kelime zannedildiğini ve ikinci kelimenin yidi 'yedi' okunma tehlikesinin doğduğunu söyledi. (Örnek: بيلكيلي يدي bilgiliyedi). Ancak bunu yedi rakamı değil /y/ yardımcı ünsüzü olarak bilgili-y-idi şeklinde okumamız gerektiğini öğretti. Bu bilgiye göre Topkapı Sarayı Oğuznâmesi'nde imlâsının ayrı yazılmasından dolayı naşirlerin hemen hemen hepsinin rakam olarak 'yedi' yidi yedi yédi okuduğu kelimenin ilk sesinin iki kelime arasında /y/yardımcı ünsüzü olarak gösterilmesi gerekiyor.

Buna göre ibareleri, şöyle okursak, cümleler düzelmekte ve anlamları açığa çıkmaktadır:

$\begin{array}{lll}\text { biliklü yédi } & \rightarrow & \text { bilgilü-y-di } \\ \text { uǵurlu yédi } & \rightarrow & \text { ug̉urlu-y-dı } \\ \text { sa`ādetlü yédi } & \rightarrow & \text { sa‘ādetlü-y-di } \\ \text { devletlü yédi } & \rightarrow & \text { devletlü-y-di } \\ \text { hürmetlü yédi } & \rightarrow & \text { hürmetlü-y-di } \\ \text { heybetlü yédi } & \rightarrow & \text { heybetlü-y-di }\end{array}$




\section{J(৫)}

Ben cümleleri şöyle okuyorum:

Dede Korkut bilgilü-y-di bilüsin vérsün

Emir Sül\{ey\}mān ug̉urlu-y-dı ug̉urın vérsün

Salır Kazan sa’ādetlü-y-di sa'ādetin vérsün

Bayındır Han devletlü-y-di devletin vérsün

Alp Arız [hürmetlü]-y-di [hürmetin] vérsün

Biğı ḳanlu Bügdüz Emen heybetlü-y-di heybetin vérsün.

Burada konu ile ilgili bir hatıramı anlatmam gerekiyor.

Yıl 1973. Orhan Şaik GÖKYAY'ın Dedem Korkudun Kitabı adlı ansiklopedik yayını çıktı. Kitabı hemen aldım ve okumaya başladım. Kısa bir süre sonra Orhan Şaik GÖKYAY, Prof. Dr. Ali ALPARSLAN'1, Prof. Dr. Mücteba İlGÜREL'i ve beni evine çay içmeye davet etti. Gittik. Hanımının ikramında Ali ALPARSLAN hocam ile güzel bir sohbeti dinledim. Daha sonra "yukarı çıkalım” dedi. Kütüphanesinin bulunduğu ikinci kata çıktık. Yeni yayımlanan Dedem Korkudun Kitabı'nı eline aldı ve konuşma ikimizin arasında geçmeye başladı. Çünkü ben Muharrem ERGiN'in asistanı idim ve benim kanaatim ona göre mühimdi. Bana "Dedem Korkudun Kitabı'nı gördün mü?" diye sordu. "Gördüm ve okudum" dedim. "Nasıl buldun?" dedi. "O Dede Korkut Kitabı değil, Dede Korkut Ansiklopedisi olmuş" dedim. Bu cevabım hoşuna gitti. "Ekler bölümündeki Oğuznâme'yi okudun mu?” dedi. "Okudum efendim" dedim. "Nasıl buldun?" dedi. "Ben otuzdan fazla kelimeyi sizden farklı okudum" dedim. "Neler onlar?" dedi. "Bir yerde örün, bir yerde urun okuduğunuz kelimeyi ben orun okudum" dedim. "Baktı, başka" dedi. Ayrıca kolhasın okuduğunuz kelimeyi ben koncasın 'goncasını' okudum dedim. Ona da baktı. "Başka" dedi. Bu sefer ben sordum. "Dede Korkut biliklü yedi bilüsin versin" okumuşsunuz. Burada "yedi" nedir?" dedim. Hemen cevap verdi. "Canım bunu bilmeyecek ne var. Üçler, yediler, kırklar”. Ben tekrar sordum. "Burada öyle mi?”. Durdu. Düşündü. "Sen nasıl okudun?" dedi. Ben cevap verdim. "Şayet müstensih biligliydi yazsaydı kelimeyi tek kelime olarak okurduk. Ancak biliklü kelimesi vav 


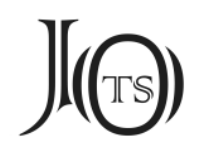

ile bitiyor. Vav harfi kendisinden sonra gelen harf ile birleşemez. O yüzden kelimenin devamı ayrı yazılmış. Ben biliklü-ydi şeklinde okudum" dedim. Durdu düşündü. "Bunları niçin yazmadın?" diye sordu. Ben cevap verdim. "Aman efendim, min gayri haddin, siz bir ansiklopedi yazmışsınız. Eserinizin ikinci baskısında bunları düzeltirsiniz" dedim. Bu sırada eşi yeni çayları getirdi. Sohbet Ali Bey ve Mücteba Bey ile devam etti.

Evden çıktı̆̆ımızda, Mücteba bana döndü. "Osman biliyorsun. Onların çocuğu yok. Sen öyle cevaplar verdin ki ihtiyarın kalbini kazandın" dedi. Gerçekten de Orhan Şaik Bey daha sonraları bana yazdığı mektuplar ile ithaflarına hep "Oğlum Osman" hitabı ile başlamıştır. Bir gün onların da fotokopisini yayımlarım.

İkinci bir husus, bilim adamı birisinin eserini değerlendirirken kişi hakkındaki düşüncelerini elbise askısına asmalı, yazısında objektif olmalı diye düşünürüm. Ancak merhum TEZCAN'ın kişiler hakkında çifte standart kullandığı görülüyor. GÖKYAY ve ERGiN için nötr, Faruk SÜMER için pozitif, Bahaeddin ÖGEL, Mustafa S. KAÇALiN için negatif ifadeler kullanmış. Benim kitabımı (2006) bibliyografyaya bile almamış, yok saymış. Bakın s. 27'de KAÇALiN hakkındaki ifadesi nasıl:

\footnotetext{
“Topkapı Sarayı Oğuznâmesi son olarak Mustafa S. Kaçalin tarafından yayımlandı. Bu yayında eski yayınlardaki yanlışlardan hiç biri düzeltilememiş, aksine Edgüer ve Gökyay'ın birkaç isabetli okuyuşu yerine yanlış okuyuşlar önerilmiştir".
}

Şimdi KAÇALiN'in okumasına bakalım (2017: 784-785):

Dede Korkut biliglü-y-idi bilüsin vérsün, Emïr Süleymān ug்urlu-y-ıdı ugurın vérsün, Salır Kazan sa'ādetlü-y-idi sa'ādetin vérsün, Bayındur Hān devletlü-y-idi devletin vérsün, Alp Arı ...-y-di ... vérsün, Bıyıgı kanlu Bügdüz Emen heybetlü-y-idi heybetin vérsün.

Kısacası metni düzelterek doğru okuyan KAÇALiN, eski yanlışı devam ettiren TEZCAN'dır.

\section{6.-28. satırlar}

yér enizin (?) yér enin yılan bilür.

burlu yonca dadın\{l\} borsuk bilür. 


\section{J(৫)}

yédi dere kolhasin dilkü bilür.

çuvaldız\{ū\} kıymetin nöker i bilür.

ag̀ır yükü̈ hengini katır bilür.

yédi yollar ayırdın deve bilür.

er aġırın er yéynisin eren bilür.

kara başa ag̉rı gelse, béyni bilür.

gen yérler[ün] otlagin geyik bilür.

datlu suyun dadın\{1\} kulan bilür.

er nākesin er cömerdin ozan bilür.

Ben bu 11 özlü sözün/atasözünün ikincisi ile üçüncüsü üzerinde durmak istiyorum.

burlu yonca dadın\{1\} borsuk bilür.

yédi dere kolhasin dilkü bilür.

TEZCAN, burlu okuduğu kelimeyi Notlar bölümü s. 183'de "burlu (< burulu) daha açılmamış henüz burulmuş durumda", bur- eyleminden edilgin durum s1fatı. (Bugünün Türkçesi dayal, döşeli, kapal, yıkahı örneklerinde olduğu gibi)" şeklinde açıklama notu yazmış. KAçALiN ise, (2017: 784-785) ibareyi pürülü yonca olarak okumuş. Pürülü kelimesini de (< pür+ü+lüg) yapraklı (Derleme Sözlüğ̈̈, IX: 3665b) şeklinde açıklamış. KAÇALín'in s. 765-766'daki 44: 10 numaralı notunda da "bürli: bürli okunup < pür+li (< pür "kimi ağaçlarda, yapraklardan sonra ayrı olarak süren ince yaprak" TDK: TTS V: 3207)" açıklaması var. Yoncanın özelliği dört yapraklısının bulunmasıdır. Bulanın talihli olduğuna inanılır. Bu bakından KAÇALiN'in "yapraklı yonca" açılaması metne daha yakışıyor.

TEZCAN, kolha okuduğu kelimenin Dresden 4b/4'te kohu, V. 59b/2'de koku şeklinde geçtiğini söylüyor ve "Sözün Dede Korkut Kitabı'ndaki biçimi açıkça anlaşı1ırken yazmada kolha ya da kulha okunabilecek şekilde yazılmış olan kelimenin araştırılması gerekiyor" kaydını düşüyor. (s. 134). 


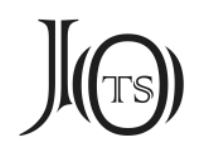

Ben de bu kayda dayanarak kelimeyi araştırıyorum. Bu kelime beş harften oluşmaktadır. İmlâsına göre ilk harf kaf (= k), ikinci harf vav (w), üçüncü harf lam, dördüncü harf hl, beşinci harf iki gözlü he olarak teşhis ediliyor. Ancak ben, bu kelimenin imlâsında müstensihin istinsah/çekimleme hataları yaptığını düşünüyorum. İlk ses olarak geçen /k / ünsüzü, / $\dot{\mathrm{g}}$ / > / k-/ gelişmesi ile / $\dot{\mathrm{g}} /$ ünsüzünden gelişmiş olmalıdır. Dede Korkut Kitabı'nda benzer örnekler vardır. Mesela, karıp < garïb (Dresden karıliǵa 267/5, 269/13), kazap < gazab (Dresden 19/10, 20/9), karım < garīm (Dresden 3/11), kayrı < gayrı (Dresden 378/5), belki karayıp < garāib (Dresden 12/5). İkinci harf/ses olarak geçen vav, kelime kalın sıralı olduğu için, /o/ veya /u/ okunabilir. Üçüncü harf olarak geçen lam harfi çekimleme yanlış1dır. Müstensih nun harfinin dişini yazmış, kelimeyi tamamlamış, harflerin noktalarını koyarken nun harfinin tek noktasını harfin tam üstüne koymuş, ancak mürekkebin akması ile nokta ile harfin dişi birleşmiş, böylece nun yerine lam harfi teşekkül etmiştir. Dede Korkut Kitabı'nda böyle mürekkep fazlasından doğan başka yanlışlar da vardır.

Dede Korkut Kitabi'nın Dresden yazmasında 8/10.-11. satırlarda,

bin söyler isen birisini ḳoymaz

erüy sözini ḳulag̉ına ḳoymaz

şeklinde istinsah edilen beytin ilk misrainda koymaz yazılan kelimenin tuymaz olarak okunmasını söylemiş ve sebebini de şöyle açıklamıştım:

\footnotetext{
"Müstensih metinde tuymaz yazmak istemiş ve yazmıştır, ancak kamış kalemi fazla bastırmaktan ve harfi sola doğru biraz eğri yaz-maktan dolayı mürekkep yığılması sebebiyle, te harfinin üstte, iki noktalı gövdesi, üstte iki noktalı kaf gövdesi halini almıştır. Burada harfi yanmış yazma yok, kaligrafik hata vardır." (2006: 150)
}

Dördüncü harfin noktası da harfin altına konularak harfi cim $(=c)$ okutacak iken, sehven harfin üzerine konmuş böylece harf $h_{l}(=h)$ olarak okunmuştur. Beşinci harf olan iki gözlü he'nin yazılışında yanlış yoktur. 


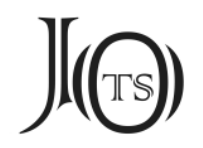

Ben, bu görüşlerime dayanarak ilk nâşirlerden TEZCAN'a kadar devam eden kolha okuyuşunu konca şeklinde okumak ve konca < gonca olarak açılamak istiyorum. Böylece üst satırdaki yonca kelimesine paralel konca kelimesini elde etmiş oluyoruz. Bana göre özlü sözler şöyle okunmalıdır:

bürülü yonca dadını borsuk bilür $(4+4+4=12)$

yédi dere koncasın<1> dilkü bilür $(4+4+4=12)$

\section{3. satir}

yédi yıl Elburza sefer ḳlan/kaydıp dönen/kııyan pusat "Yedi y1l Elburza sefer k1lan / Geri dönüp gelen Kıyan Busat”. Dede Korkut Kitabı'nda başından beri (بساط) BSAṬ basāṭ okunan kişi adı bir hayal kelimedir (ghost word). Bu kişi adının Topkapı Sarayı Oğuznâmesi'ndeki gibi BWSAṬ būsāṭ şeklinde okunması için bk. Sertkaya 2007: 449-453.

\section{4. satir}

Ban Ḥișārından barlayub uçan "Ban hisarından zıplayıp aşağı atlayan". Cümledeki barlayub uçan ibaresi "zıplayıp aşağı atlayan" anlamına gelmez. Dresden yazmasında Beyreğin Bayburd hisarından kaçması olayı şöyle anlatılır. (D 97/10 $-99 / 1)$

\footnotetext{
"Meger kâfir béginüy bir bikir kızı vardı. Her gün beyregi görmege gelürdi. Ol gün gerü görmege geldi. Bakdı gördi Beyrek saht olmuş. Kız eydür: Niçün sahtsın hanum yigit? Geldügümce seni şén görürdüm. Gülerdüy oynardın, şimdi n’olduy dédi. Beyrek eydür: Nice saht olmayayım. On altı yıldır kim babayuy tutsakıyam. Ataya anaya kavuma kardaşa hasretem ve hem bir kara gözlü yavuklum vardı. Yalancı oglı Yaltacuk dérler bir kişi vardı. Varmış yalan söylemiş. Beni öldi démiş. <yavuklum> aya varur olmış dédi. Böyle dégeç kız Beyregi âşıklamışdı. Eydür: eger seni hisardan aşaga urganla salınduracak olursam, babana anaya sağlık ile varacak olursay, beni bunda gelüb halallıga alur mısın dédi. Beyrek and içdi. Kılıcuma togranayın, ohuma sancılayın, yér gibi kertileyin, toprak gibi savrılayın, saglıgla varacak olursam Oguza, gelüb seni halallıga almazsam, dédi. Kız dahı urgan getürüp Beyregi hisardan aşaga salındurdı. Beyrek aşaga bakdı kendüzin yer yüzinde gördi. Allaha şükr eyledi."
}

Beyrek için metinde geçen Parasaruy Bayburt Hisarından parlayub uçan ifadesi mecazî ifadelerdir. 


\section{J(৫)}

Kelimelerin etimolojik açıklamasını yapalım. Osmanlı Türkçesinde Farsça per perr kelimesi 'kanat' demektir. بپ par, parr 'a wing' [kanat] (Steingass 1930: 239a). بـ par 'a wing' [kanat] (Johnson 1852: 278b).

Kelimenin kullanılışının son örneklerinden birisi Tevfik Fikret'in Rübâb-ı Şikeste adlı eserinin girişindeki dörtlükte görülür.

Kimseden ümmîd-i feyz etmem, dilenmem perr ü bâl

Kendi cevvim kendi eflâkimde kendim tâirim

İnhinâ tavk-1 esâretden girândır boynuma

Fikri hür irfanı hür vicdanı hür bir şâirim.

Dolayısıyla perle- 'kanatlanmak' demektir. Uç- fiili ile birlikte kullanılır. Perleyüp uçmak 'kanatlanıp uçmak' mecazen 'hisardan kaçmak' anlamına gelir, 'zıplayıp aşağı atlamak' anlamında değildir. Çünkü hisar çok yüksektir. Beyrek aşağıya, yeryüzüne ancak urgan ile inmiştir, zıplayarak aşağı atlamamıştır.

Kelimenin Azerbaycan Türkçesindeki telaffuzu ise kalın sıralıdır. Naşirler parlayub şeklinde okunmuşlardır. Azerbaycan Türkçesinde onomatophe olarak şöyle yer almıştır:

"pırıldamak 'kanatları ile pırıltı sesi çıkararak "pırr” ederek uçmak (kuşlar hakkında)', bk.

pırıldaşmak, pırıltı. (Orucov 2006a: 600b)

Türkiye Türkçesi’nde de Derleme Sözlüğü 8397'de, kalın sıralı olarak verilen, sazların arkasından bir keklik havaya doğru parladı örneğindeki parla- 'uçmak' olarak verilmiştir.

\section{6.-47. Satırlar}

Bay Böre oglı Beg Barı yigit cümlesinde Barı şeklinde geçen isim barı<yek> veya bark<yik> olarak tamamlanabilir. Dresden'de Beyrek ve Bayrek, Vatikan'da ise Bayrek, Baryek ve Baryik şekillerinde geçen kişi adı için TEZCAN şunları söylüyor (s. 228-229): 


\section{$J(\Theta)$}

"Dört değişik biçimde yazılmış olan ad şimdiye değin açılanabilmiş değildir ve nereden geldiği de başı başına bir sorundur. Kahramanın adını açılamak için şu olasılıkları sıralayabilirim.

1. Farsça bārī yek "Allah bir”. Bazı metinlerde bunun Türkçe karşıllı̆̆ bir Allāh geçer. Azerbaycan Türkçesinde bir Allāh yemin ederken kullanılan bir deyimdir. Türkiye Türçesindeki "Allah çarpsin" gibi.

2. Türkçe bay yegrek. Başka metinlerden rastlanmayan bu söze bay "zengin" ile yegrek "üstün, daha iyi” kelimelerinin bir araya getirilişi olarak açıklanabilir.

3. Türkçe *berkrek "daha sert, daha çetin". Türkçe berk "sert" üzerine 'daha" anlamına verin +rek pekiştirme ekinin getirilmesi ile: *berk+rek > bekrek > begrek > beyrek gelişimi sonucu.

Bu çözümlerin hiçbiri tam olarak tatmin edici değildir. Şu anki bilgilerimizle bir çözüme ulaşılacağını sanmıyorum.

Begrek kelimesinin çözümü için bk. Sertkaya 2014: 101-114.

\section{8. satir}

Aslanıla boġasın buğrasin göreşçisin öldüren cümlesi sehven "Arslanıyla boğasını, güreşçisini öldüren" şeklinde verilmiş. Metindeki buggra kelimesi atlanmış. Metne göre çevirinin "Arslanıyla boğasını, buğrasını, güreşçisini öldüren” şeklinde olması gerekirdi.

\section{9. satir}

sarı donlu Selcen kadın "Sarı elbiseli Selcen Kadın", maddesinin açıklamasında kadın adının çeşitli kişiler tarafından Salcan Selcen Selcan gibi şekillerde okunduğunu söyleyerek Faruk SÜMER'in çalışmasından bahsedilmiştir. "Selcen veya Selcan adı hakkında inandırıcı bir açıklama bilmiyorum" diyen TezcaN'ın Fatma ÖZKAN’ın bu konudaki yazısını atladığı anlaşılmaktadır. Bk. Özkan 1995: 907-914.

\section{1. satır}

Ṭokuş Koca og̉h Ṭogrul sulțān "Tokuş Koca oğlu Tuğrul Sultan”, maddesinde togrul kelimesinin denazalizasyon (aykırı genizleşme) yolu ile toğrul şeklinde gelişmesi ile ilgili ünsüz çizelgesini ben bir yazımda (1991: 321-325) yayımlamıștım. 


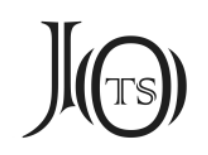

Ancak nazalizasyon/denazalizasyon (genizleşme/aykırı genizleşme) konusu Ayşegül SERTKAYA tarafından (2014: 1-12) çok daha geniş bir şekilde anlatılmakta ve açılanmaktadır.

Dom edik\{lü\} duma donlu 'sağlam çizmeli, zırh giyimli' maddesinde geçen dom kelimesi için bk. Sertkaya 2016: 1063-1093.

\section{5.-60. satırlar}

Kazan ile ilgili iki soylama, 60.-65. satırlarda yer alan metin ise Dede Korkut Kitabı'nın Dresden yazması ile Günbed yazmasında varyantları olan bir soylamadır. Soylama metninin son neşri için bk. Uçar 2020: 213-240.

Sonuç olarak merhum Semih TEZCAN'ın Topkapı Sarayı Oğuznâmesi adlı incelemesi iyi bir dilcinin hazırladığı başarılı bir eserdir. Keşke sağ olsaydı ve eserini tamamlayarak yayımlandığını görseydi. Yüce Tanrı'nın rahmeti üzerine olsun.

\section{Kaynakça}

Johnson, F. (1852). A Dictionary, Persian, Arabic, and English, London: W. H. Allen and Co. Ltd.

KaÇALIn, M. S. (2017). Oğuzların Diliyle Dedem Korkudun Kitabı, Ankara: Türk Dil Kurumu Yayınları.

ORucov, E. (2006a). Azerbaycan Dilinin İzahlı Lüğeti III, Bakı: Şerq-Qerb.

ORucov, E. (2006b). Azerbaycan Dilinin İzahlı Lüğeti IV, Bakı: Şerq-Qerb.

ÖZKAN, F. (1995). “Selcen Adı Hakkında”, Türk Dili, 524: 907-914.

SERTKAYA, A. (2014). “Köl Tigin, Tonyukuk, Bilge Kağan, Ongi, Taryat, Şine Usu gibi Göktürk Harfli Yazıtlarda Aykııı Genizleşme (Denazalizasyon) Örnekleri”, Gazi Türkiyat: Türkoloji Araştırmaları Dergisi, 15: 1-12.

SERTKAYA, O. F. (1991). “Okay 'Zühal/Satürn' mü, Yoksa 'Müşteri/Jüpiter' mi?”, Türk Dili, 474: 321-325.

SertKayA, O. F. (2006). Dede Korkut Kitabı, Dresden Nüshasının “Giriş" Bölümü, (Metnin Transkripsiyonu ve Açıklama Notları), İstanbul: Ötüken Yayınları. 


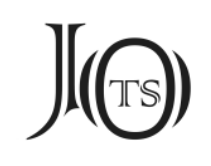

SertKayA, O. F. (2007). "Kitâb-1 Dede Korkut'ta Basat Okunan İsim Üzerine Yeni Görüşler”, Ortak Türk Keçmişinden Ortak Türk Geleceyine, V. Uluslararası Folklor Konferansı Materialları, Bakı: 449-453.

SERTKAYA, O. F. (2014). “Adana, Begrek > Beyrek ve Elma Kelimelerinin Kökeni Üzerine”, Ankara Üniversitesi Dil ve Tarih-Coğrafya Fakültesi Türkoloji Dergisi, 19/2: 101114.

SERTKAYA, O. F. (2016). “Tüm Kelimesi Üzerine Yeni Değerlendirmeler”, Teke: Uluslararası Türkçe Edebiyat Kültür Eğitim Dergisi, 19: 1063-1093.

STEINGASS, F. J. (1930). A Comprehensive Persian-English Dictionary, Including the Arabic Words and Phrases to be Met with in Persian Literature, Second Impression, London: Kegan Paul, Trench, Trubner \& Co. Ltd.

UÇAR, E. (2019). “Dede Korkut Anlatmalarındaki Ban Üzerine”, Anasay, 10: 21-42.

UçAR, E. (2020). “Dede Korkut Kitabi'ndaki Bir Soylama Üzerine”, Eski Türk Edebiyatı Araştırmaları Dergisi, 3/1: 213-240. 